\title{
Vertical Violence Between Staff Medical Surgical Nurses and \\ Nursing Students During Clinical Rotations
}

Lisa Cunningham

Dominican University , 2015

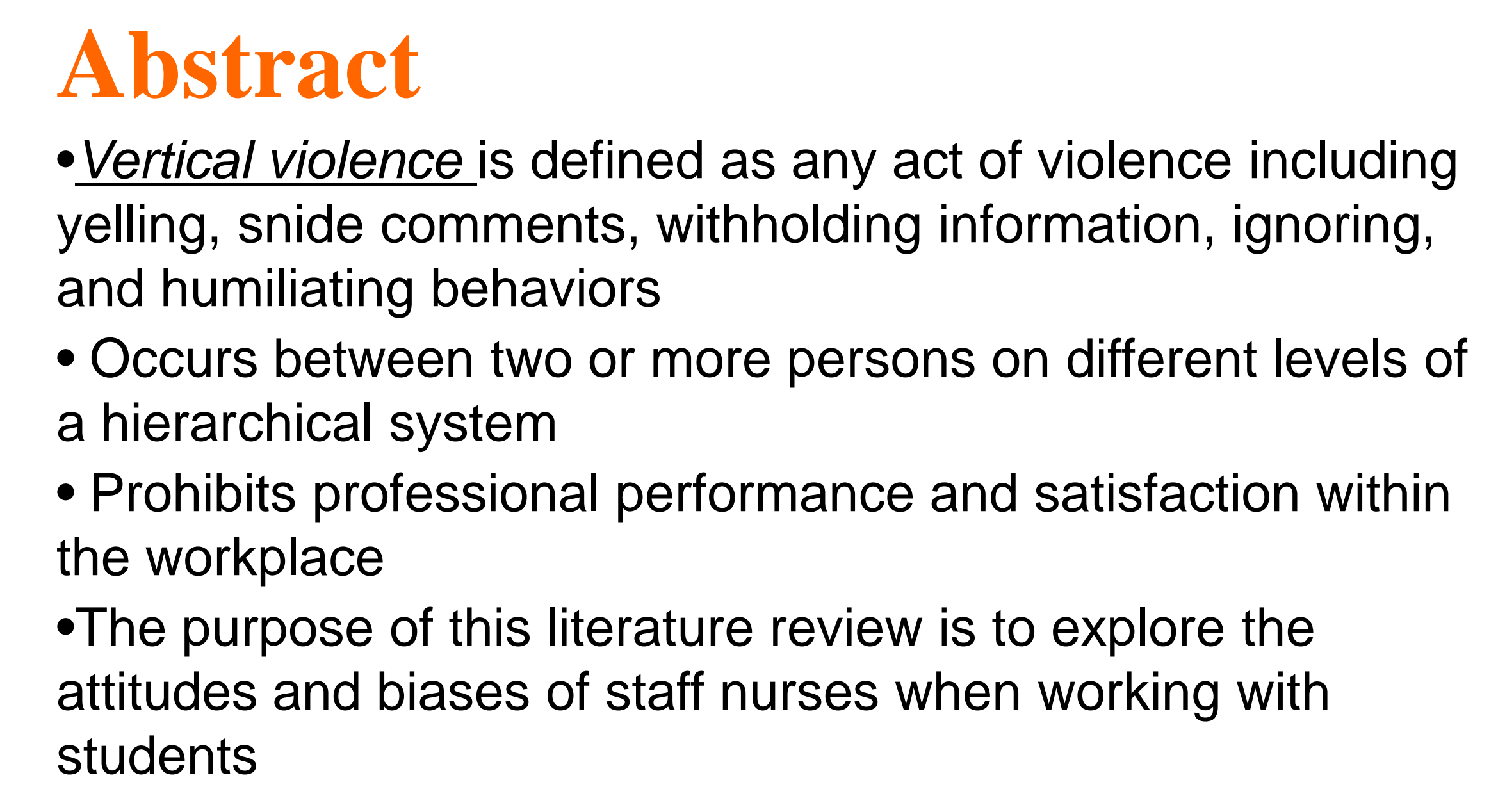

(Cantey, 2013)

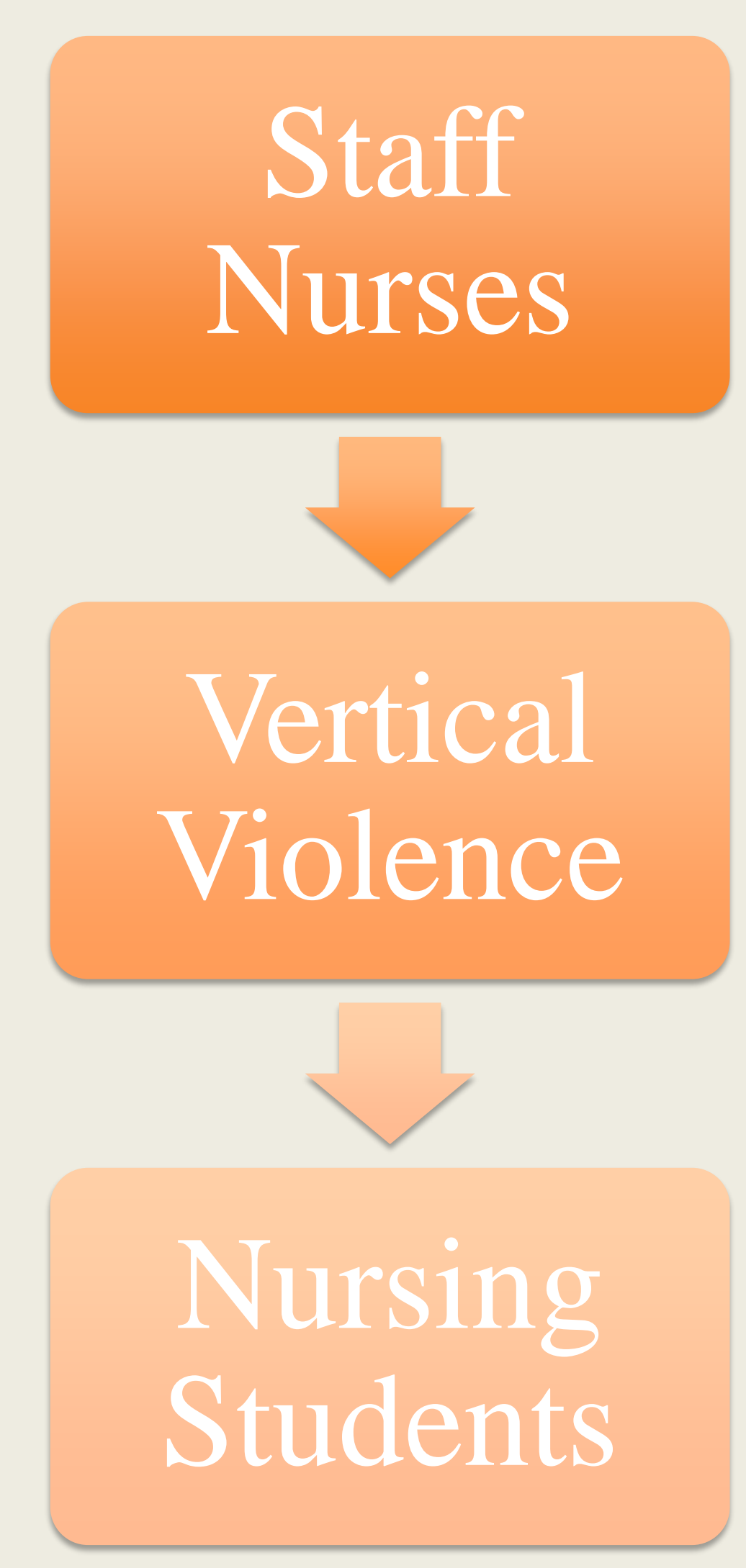

Problem Statement - Vertical violence is an ongoing problem in the nursing

-Affects hospital units where newly graduated nurses are needed the most. - Gap of knowledge of why staff nurses are holding biases against the students, and how communication and
teamwork between the two can be improved.

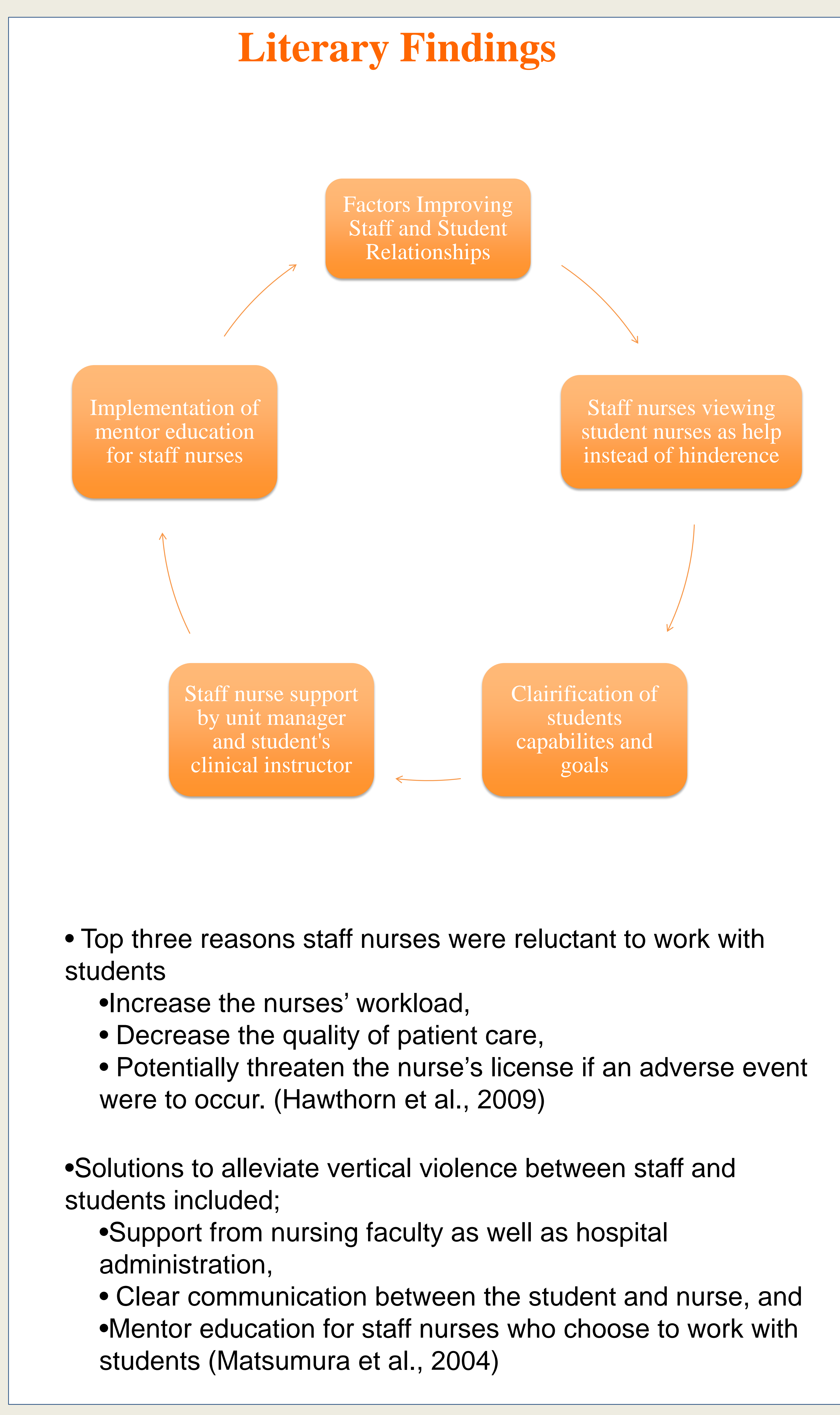

Research Proposal

- Descriptive survey quantitative design - Implementation of mentor education program at San Francisco General Hospital

- Strategies in increase communication and incorporation of students

-Pre/Post test survey

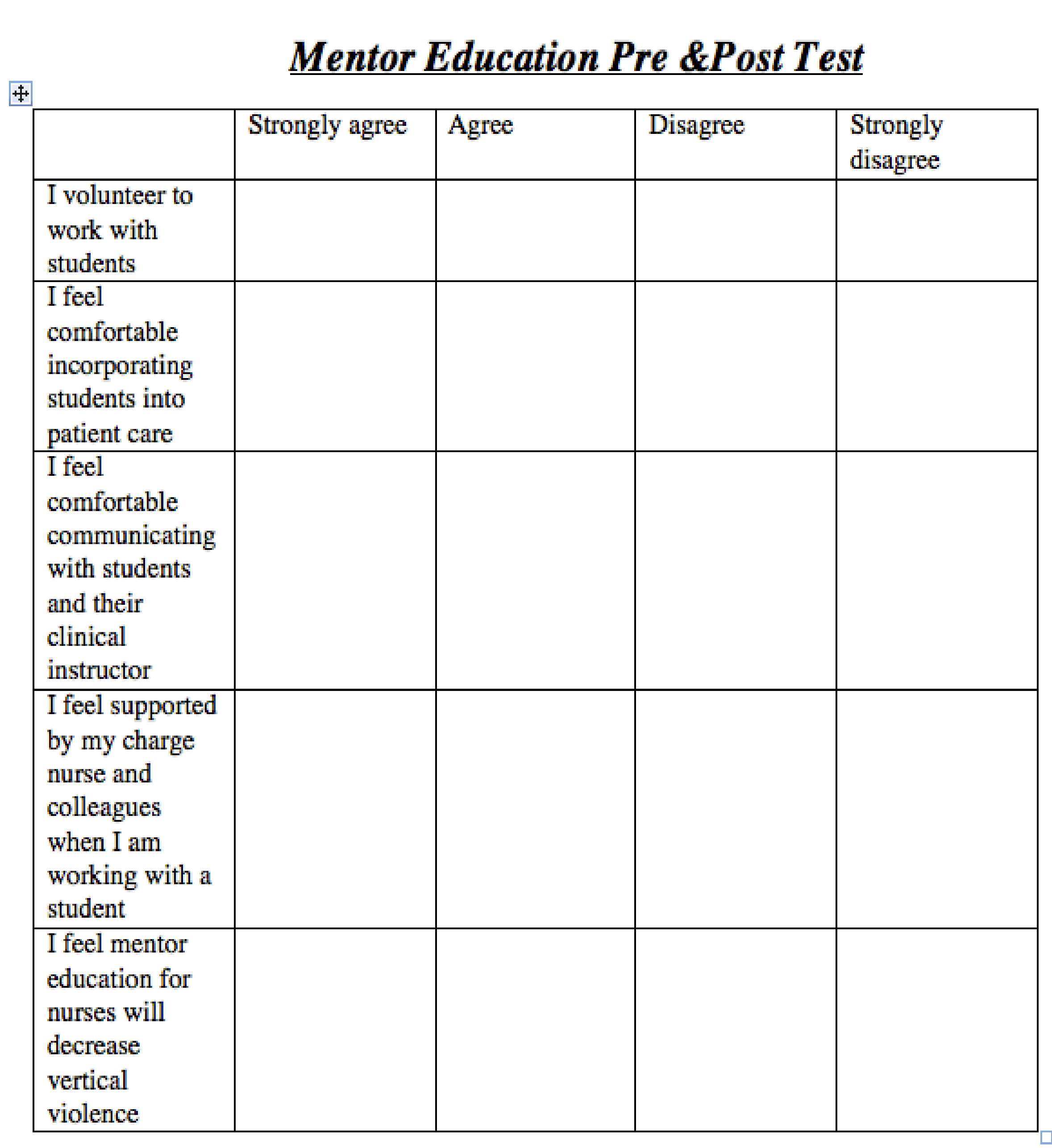

Indications For Clinical Practice •Decrease vertical violence among staff and students -Decrease hospital attrition rates

-Promote a safe and positive learning environment for students

Promote continuing education for staff nurses

Promole a stronger generation or new nurses

Literature cited

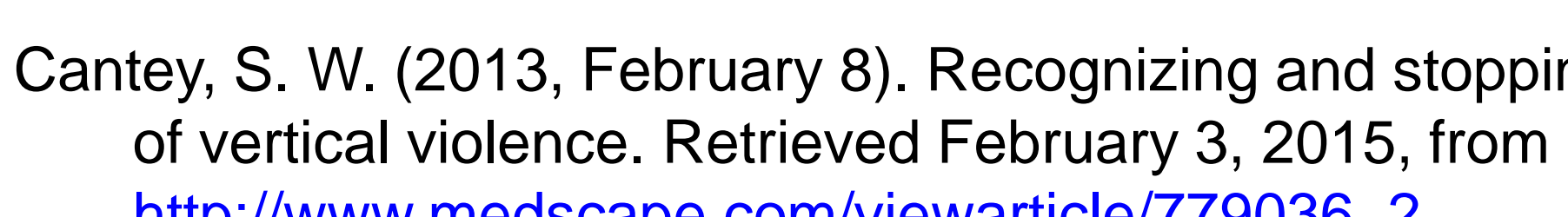

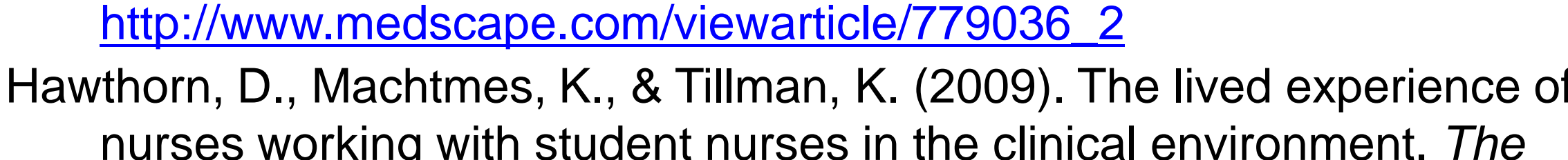

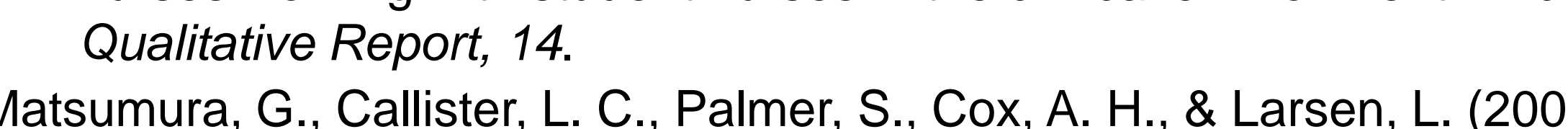

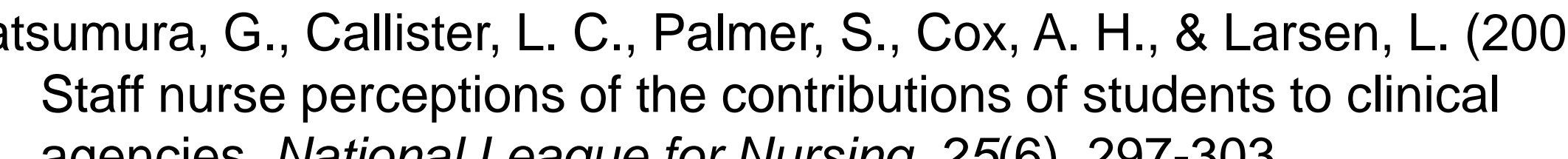

A special thanks
A special thank you to Dr. Linnard-Palmer for the support and guidance in writing the literature review and research proposal 